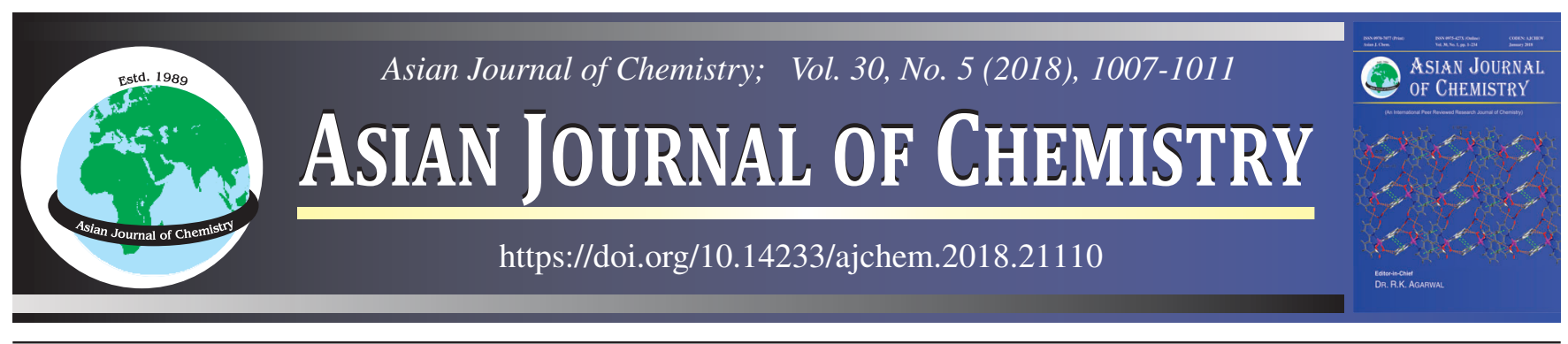

\title{
Furfural Production from Mile-a-Minute Weed (Mikania micrantha) Using Organic Acid from Bilimbi (Averrhoa bilimbi)
}

Taslim ${ }^{*}$, Meutia Mirnandaulia, Iriany and Rondang Tambun

Department of Chemical Engineering, Faculty of Engineering, Universitas Sumatera Utara, Medan 20155, Indonesia

*Corresponding author: E-mail: taslim_hr@yahoo.co.id

Received: 28 October 2017;

Accepted: 24 January 2018;

Published online: 29 March 2018;

AJC-18830

\begin{abstract}
Mile-a-minute weed (Mikania micrantha) is an invasive weed with rampant growth which seriously damages the ecosystem. One promising way to control mile-a-minute weed by utilizing it for furfural production because waste of mile-a-minute weed contains a lot of pentosane. In this work, fufural synthesized by using bilimbi (Averrhoa bilimbi) which is an organic acid and environmentally friendly. In this study, mile-a-minute weed (100-70 mesh size), bilimbi acid and salt $(\mathrm{NaCl})$ were reacted in a three neck round bottom flask at $80-140{ }^{\circ} \mathrm{C}$ for 120-330 min. The weight (mile-a-minute weed) to volume (bilimbi acid) ratio was set to be 1:6 at fixed solution volume of $750 \mathrm{~mL}$. Furfural was extracted from water using solvent extraction method employing chloroform as a solvent. After extraction the lower layer would contain furfural and chloroform while the upper layer would contain water. Furfural was purified by evaporating chloroform. The furfural was identified by the acetic aniline colour reaction, infrared spectrophotometer and GC-MS. The highest furfural yield was obtained at $7.2 \%$ for the reation temperature of $100^{\circ} \mathrm{C}$ and reaction time of $300 \mathrm{~min}$.
\end{abstract}

Keywords: Mile-a-minute weed, Hydrolysis, Bilimbi acid, Sulfuric acid, Fulfural.

\section{INTRODUCTION}

Mile-a-minute weeds (Mikania micrantha) is a malignant weeds that can damage agriculture, vacant land, pastures, forest and plantation such as palm oil, tea, coconut and pine [1,2]. Mile-a-minute weed is very difficult to eradicate because it can multiply vegetatively by stem cuttings and generative by seed with anemochory [2]. Mile-a-minute weeds grow on other tall plants. If mile-a-minute weeds are not controlled it will cover other plants which will cause the plants to die for lack of sunlight [3-5]. Mile-a-minute weed can be controlled by three methods viz., physical methods by means of periodic pruning, chemical methods using herbicides and biological method using competing vegetation such as tall grass [6,7]. Pruning is an easy and effective way to control mile-a-minute weed compared to other methods. However, pruning generates a lot of waste which, when left untreated, could grow vegetatively [8]. One way to solve this problem is to utilize lignocellulosic on mile-a-minute weed waste [9-11]. The composition of milea-minute weed is $56.04 \pm 0.86 \%$ pentosane, $14.05 \pm 0.18 \%$ hollocellulose and lignin $23.4 \pm 0.89 \%$ [12]. Mile-a-minute weed contains higher pentosane than corn cobs, bagasse, rice husk and others [13]. Pentosane can be synthesized into furfural which is widely used as intermediates and raw material in the oil refinery industry, plastics, pharmaceuticals, agrochemicals, and can be developed into biofuels and bioplastics $[14,15]$.

Production of furfural is limited to raw materials such as corncob [16,17], oil palm fronds biomass [18], rice hulls [19], bagasse [20], olive tree [21], eucalyptus [22], waste pulp [23], sorghum straw [24], rice straw [25], beech [26], birch wood [27], algae and seaweed [28]. So far, there has been no study of furfural that use mile-a-minute weeds as raw material.

In the industrial production of furfural from biomass feedstock, the catalyst used is usually derived form other types of acids as sulfuric acid [27,29,30], hydrochloric acid [31], phosphoric acid [32,33] and formic acid [34]. The use of sulfuric acid has several disadvantages such as formation of residues that contaminate the environment, energy intensive and corrosion of equipment used [35-38]. One of the obstacle in furfural industry is no environmentally friendly chemical process technology [39]. In this study, bilimbi acid, which contains citric acid, oxalic acid, acetic acid and formic acid is used as the catalyst. The acidity of bilimbi acid depends on the season and fruit ripeness [40,41]. Bilimbi acid has $\mathrm{pH}$ ranges 0.9 to 1.5 and showed the presence of $\mathrm{H}^{+}$ions that function in hydrolyzed biomass $[42,43]$. The reaction mechanism of furfural production is depicted in Fig. 1.

The use of bilimbi acid has not been studied, therefore, this research focused on furfural production from mile-a-minute 


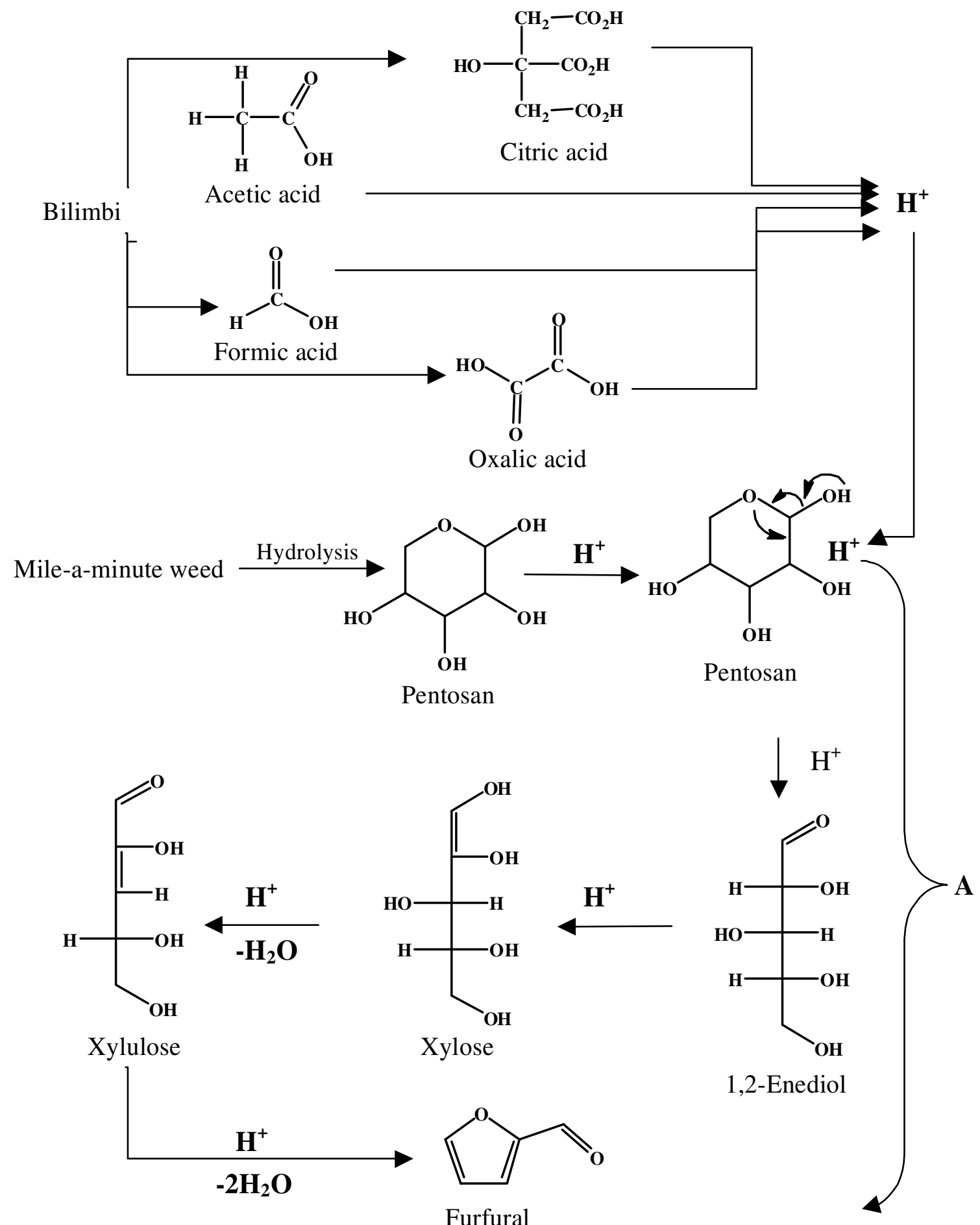

Fig. 1. Formation of furfural [Ref. 44]

weed by using bilimbi acid as comparison concentration sulfuric acid $20 \%$ was used as catalyst at $120^{\circ} \mathrm{C}$.

\section{EXPERIMENTAL}

Mile-a-minute weed and bilimbi was obtained from banana fields in Medan, Indonesia. Sodium chloride and $\mathrm{H}_{2} \mathrm{SO}_{4}$ were purchased from Merck.

Preparation of mile-a-minute weed powder: Preparation of mile-a-minute weed powder was based on method used by Ko et al. [12] with slight modifications. First, mile-a-minute weed was cleaned from impurities with water until $\mathrm{pH}$ was reached constant then it was cut to $\pm 1 \mathrm{~cm}$. Afterwards, it was dried in oven at $100{ }^{\circ} \mathrm{C}$ for $2 \mathrm{~h}$, then milled in a ball mill for $3 \mathrm{~h}$. To uniform particles size sieving flour conducted using 100-70 meshes and stored in ziplock plastic at ambient temperature.

Extraction of bilimbi (Averrnoa bilimbi): Extraction of bilimbi acid followed the procedure reported by Thamizhselvam et al. [45] with slight modifications. Bilimbi was cleaned from impurities with water until the $\mathrm{pH}$ of the water is contant then pulverized using a commercial blender to obtain bilimbi juice. The juice was filtered throughWhatman filter paper No. 41. A clear filtrate was obtained and stored in the refrigerator at $0{ }^{\circ} \mathrm{C}$. 
Synthesis of furfural: Furfural was synthesized using the procedure reported by Shafeeq et al. [46] with slight modifications. Mile-a-minute weed (100-70 mesh size), bilimbi acid and salt $(\mathrm{NaCl})$ were added into the three-neck round bottom flask. The flask was then connected to a long vertical tube to provide sufficient length for furfural vapour. This long tube was connected to condenser and furfural vapour was collected in a flask. The mixture was heated with a hot plate at $(80,100,120$ and $\left.140^{\circ} \mathrm{C}\right)$ for $(120,150,180,210,240,270,300$ and $330 \mathrm{~min})$. Mile-a-minute weed to bilimbi acid ratio was set to $1: 6(\mathrm{w} / \mathrm{v})$ at fixed solution volume of $750 \mathrm{~mL}$. Furfural was extracted from water using solvent extraction method by employing chlorofrom as solvent. After extraction, the lower layer would contain furfural and chloroform while the upper layer would contain water. Finally, furfural was separated by evaporating chloroform.

As reference in this study, concentration of $20 \%$ sulfuric acid was used as catalyst. The ratio of raw material and sulfuric acid is $1: 5(\mathrm{w} / \mathrm{v})$. The weight ratio of raw materials and $\mathrm{NaCl}$ is 1:1 (w/w). Reaction was carried out at total volume of $750 \mathrm{~mL}$ and temperature of $120^{\circ} \mathrm{C}$.

Identification of furfural: Furfural was identified with a colour test with aniline acetate reagent (1:1), Fourier transform infrared (FTIR) spectroscopy and gas chromatography with mass spectrophotometer (GC-MS) Shimidzu QP 2010 Brands. GC-MS was operated at $250{ }^{\circ} \mathrm{C}$. The injection port was maintained at $300{ }^{\circ} \mathrm{C}$ and the sample was injected with split less mode followed by purge at 1 min after the injection. The column temperature was held at $100{ }^{\circ} \mathrm{C}$ for $10 \mathrm{~min}$ then increased to $300^{\circ} \mathrm{C}$ at a rate of $10^{\circ} \mathrm{C} / \mathrm{min}$. The final temperature was held for $30 \mathrm{~min}$.

\section{RESULTS AND DISCUSSION}

Preliminary analysis of mile-a-minute weed: Early analysis includes moisture and pentosane level analysis. The result indicated that mile-a-minute weed contains much water. The water content of mile-a-minute weed stem was $84.10 \%$ and that of leaf was $90.01 \%$. Pentosane level was $49.54 \%$ close to that literature it $56.04 \pm 0.86 \%$.

Effect of reaction time on furfural yield: As shown in Fig. 2, furfural formation began after 120-150 min of reaction for bilimbi catalyst at all reaction temperature while for the sulfuric acid catalyst furfural formed in $30 \mathrm{~min}$. At $120^{\circ} \mathrm{C}$, the yield of furfural produced using the catayst of bilimbi was lower than that using sulfuric acid catalyst, because the acid number of sulfuric acid is 15 times larger than the acid number of bilimbi. The higher number of $\mathrm{H}^{+}$ions in sulfuric acid increases the rate of furfural formation compared to that of bilimbi catalyst. Comparison of catalyst used in the production of furfural is listed in Table-1.

At 80 and $100^{\circ} \mathrm{C}$, furfural formation began after $150 \mathrm{~min}$, while at 120 and $140^{\circ} \mathrm{C}$, furfural formation started after $180 \mathrm{~min}$. The high temperature of 120 and $140^{\circ} \mathrm{C}$ has greater influences

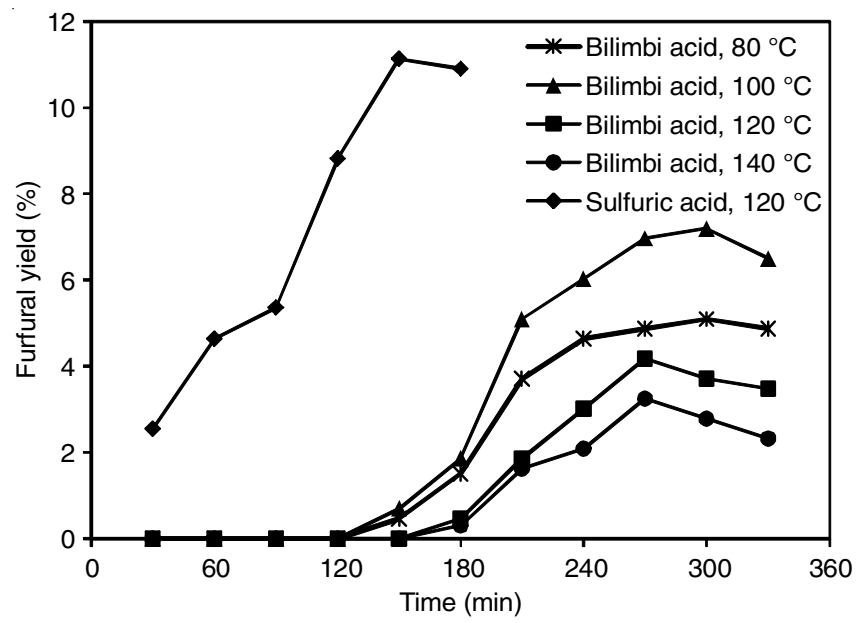

Fig. 2. Effect of time reaction on furfural yield at different temperatures

on water evaporation than furfural formation. From previous research $[47,48]$, the optimum temperature for furfural formation from pentose sugars using organic acids such as formic acid is $100^{\circ} \mathrm{C}$.

Furfural is a major product of the decomposition of glucose and xylose. The formation of glucose is primarily by hydrolysis of cellulose and xylose produced by hydrolysis of hemicellulose. Hydro-lysis of hemicellulose also produce acetic acid and arabinose. In this study, organic acid contained in bilimbi does not require high temperature but a long time of $5 \mathrm{~h}$ is required to hydrolyze pentosane in mile-a-minute weed with the highest yield obtained at $7.192 \%$ at $100{ }^{\circ} \mathrm{C}$.

At constant temperature, furfural yield increases with time due to longer contact between reaction, forming more furfural [49]. Longer time leads to lower hydrolyzate $\mathrm{pH}$ and increase rate of furfural formation due to acetic acid formation which serves as an internal catalyst. At $100^{\circ} \mathrm{C}$, for reaction time of 240 to $300 \mathrm{~min}$, the yield of furfural increased only slightly while for $330 \mathrm{~min}$ of the reaction, the yield of furfural decreased to $6.46 \%$. This decrease can be attributed to polymerization reaction resulting in furfural degradation to organic compounds, such as acetic acid and methanol [50].

Sulfuric acid enables quicker furfural production and higher increase overtime. At concentration sulfuric acid $20 \%$ is a strong acid with a pH 0.2 , an acid value $\pm 222.83 \mathrm{~g} / \mathrm{g}(2.2695$ $\mathrm{N})$. It has more $\mathrm{H}^{+}$to hydrolyze pentosane compared to bilimbi acid. Yield is highest at $150 \mathrm{~min}$ with a value of $11.13 \%$. After $180 \mathrm{~min}$, a decrease in the yield of furfural was observed, possibly because furoate acid was formed as result of the breakdown of the aldehyde group and formed kind of black resin.

In this study, the production of furfural from mile-a-minute weed using $20 \%$ sulfuric acid catalyst resulted in a yield of 11.13 $\%$ which is higher than the yield generated on other research at $8.3 \%$ under the same conditions [46]. This suggested that mile-a-minute weed contains more pentosane than corn cobs.

TABLE-1

COMPARISON OF CATALYST IN FURFURAL PRODUCTION

\begin{tabular}{cccccc}
\hline Catalyst & Volume $(\mathrm{mL})$ & $\mathrm{pH}$ & Normality $(\mathrm{N})$ & Numbers acid $(\mathrm{g} / \mathrm{g})$ & Highest yield $(\%)$ \\
\hline Bilimbi acid & 600 & 2.1 & 0.1469 & 13.99 & $7.192\left(100{ }^{\circ} \mathrm{C}, 300 \mathrm{~min}\right)$ \\
Sulfuric acid & 250 & 0.2 & 2.2695 & 222.83 & $11.13\left(120{ }^{\circ} \mathrm{C}, 150 \mathrm{~min}\right)$ \\
\hline
\end{tabular}


Furfural analysis: Furfural was identified qualitatively using reagent aniline acetate at ratio aniline and acetate of 1:1 $(\mathrm{v} / \mathrm{v})$. Furfural was identified by a colour change to red brick. For samples with reaction time of $30 \mathrm{~min}$ to 150 minutes, no colour change was observed. The colour remained yellowish like the colour of reagent aniline acetate because furfural not condensed with aniline to form an annelead compound hydroxy glutaconic dialdehyde and there was no breaking ring form an aldehyde furfural. Sample at $180 \mathrm{~min}$ started to form dark red colour, indicating the formation of furfural. However, all the samples turned dark red, indicated that furfural was formed by $30 \mathrm{~min}$ of the reaction. This proves that sulfuric acid does not take a long time for the reaction.

Based on IR spectra (Fig. 3), aldehyde group in furfural was spotted as evidenced by $\mathrm{C}=\mathrm{O}$ stretching vibration (1700$\left.1600 \mathrm{~cm}^{-1}\right)$ and $\mathrm{CH}$ aldehydes $\left(2860-2800 \mathrm{~cm}^{-1}\right)$ represented by the peak at 1674.52 and $2851.07 \mathrm{~cm}^{-1}$, respectively for sulfuric acid and bilimbi acid as catalysts. The presence of $\mathrm{C}=\mathrm{C}$ aromatic stretching vibration (1600-1475 $\mathrm{cm}^{-1}$ ) was evidenced in the area around $1521.45 \mathrm{~cm}^{-1}$. Stretching vibration peak at around $1166 \mathrm{~cm}^{-1}$ on sample using bilimbi acid catalyst supported C-O-C bonds (1200-1100 $\left.\mathrm{cm}^{-1}\right)$ within the molecular structure of furfural, while for sulfuric acid catalyst, same occurrence was present at vibration peak of $1176 \mathrm{~cm}^{-1}$. Based on the standard vibration value of furfural, it can be concluded that the compound resulting from mile-a-minute weed hydrolysis was furfural as the spectra were virtually identical to the standard vibrations of furfural [51].

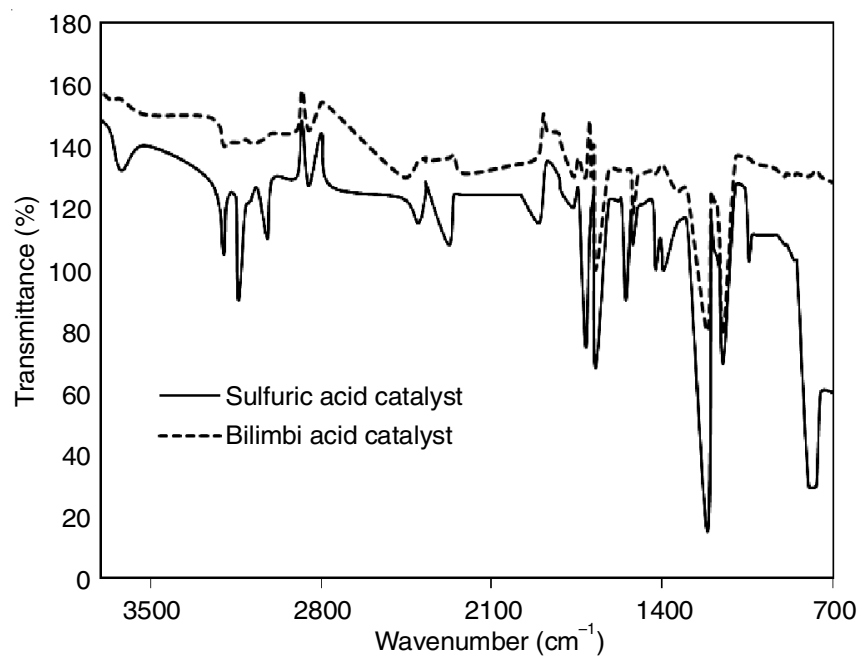

Fig. 3. FTIR analysis of furfural produced using bilimbi acid and sulfuric acid as catalyst

Analysis using gas chromatography mass spectrophotometer further confirmed that furfural was formed (Fig. 4). For bilimbi acid catalyst, furfural was detected in peak 2 with retention time 3.386 min as 2,5 furandione, 3-ethyl-4-methyl furfural which shows class of furfural. For sulfuric acid catalyst, furfural was detected in peak 3 with retention time of $3.283 \mathrm{~min}$ as 2,5furandione. Furandione belongs to furfural, it shows that the result obtained are furfural. It is also worth noting that for bilimbi acid catalyst, the high peak 23 identified as tetratetracontane are volatile compounds used as inflammatory compounds and antianalgesic.

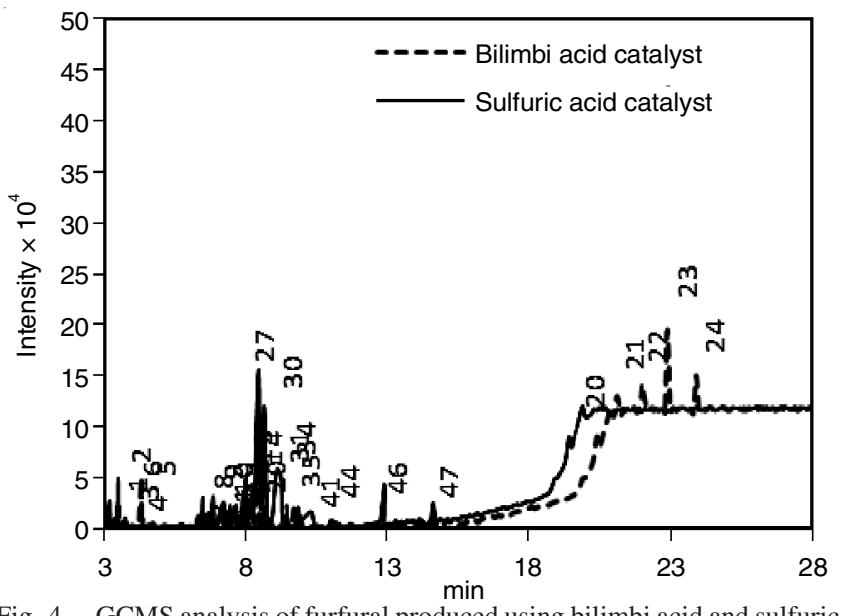

Fig. 4. GCMS analysis of furfural produced using bilimbi acid and sulfuric acid as catalyst

\section{Conclusion}

The best conditions for synthesizing furfural from milea-minute weed using bilimbi acid as catalyst is at $100{ }^{\circ} \mathrm{C}$ for 300 min which yielded $7.2 \%$ furfural. Sulfuric acid produced a higher yield than bilimbi acid at $11.13 \%$. The qualitative identification of furfural is confirmed by using test colours which indicated the presence of furfural. The FTIR showed the presence of aldehyde group, which indicated the vibrational bands of furfural at 1674.52 and $2851.07 \mathrm{~cm}^{-1}$. GC-MS results also confirmed the presence of furfural and furandione corresponds to the peak 3.386 for bilimbi and 3.283 for sulfuric acid catalyst.

\section{REFERENCES}

1. L.G. Holm, D.L. Plucknett, J.V. Pancho and J.P. Herberger, The World's Worst Weeds; Distribution and Biology, University Press of Hawaii, Honohulu (1997).

2. K.V. Sankaran, T.V. Sajeev and T.A. Suresh, Invasive Plant Threats to Forest in the Humid Tropics: A Case Study from Kerala State, India, In: Invasive Alien Species Management, National Trust for Nature Conversion, Nepal, pp. 7-17 (2014).

3. L.Y. Zhang, W.H. Ye, H.L. Cao and H.L. Feng, Weed Res., 44, 42 (2004); https://doi.org/10.1111/j.1365-3180.2003.00371.x.

4. A. Sullivan, A.M. York, L. An, S.T. Yabiku and S.J. Hall, For. Policy Econ., 80, 1 (2017); https://doi.org/10.1016/j.forpol.2017.03.001.

5. M. Siwakoti, Our Nat., 5, 1 (2008); https://doi.org/10.3126/on.v5i1.801.

6. S. Zhou, P. Chen, M. Li, L. Gao, W. Xian, Z. Wu and W. Fu, Biochem. Syst. Ecol., 65, 238 (2016); https://doi.org/10.1016/j.bse.2016.01.002.

7. M.J.W. Cock, C.A. Ellison, H.C.Evans and P.A.C. Ooi, Proceedings of Xth International Symposium on Biological Control of Weeds, Montana State University, Bozeman, USA, pp. 155-167 (2000).

8. R.W. Barreto and H.C. Evans, Mycol. Res., 99, 343 (1995); https://doi.org/10.1016/S0953-7562(09)80911-8.

9. $\quad$ N. Reddy and Y. Yang, Bioresour. Technol., 99, 2449 (2008); https://doi.org/10.1016/j.biortech.2007.04.065.

10. L.Y. Chen, Y.C. Lin, T.L. Wu, J.M. Chung, Y.T. Chen, H.T. Yang, C.H. Chen and H.J. Wu, BioResources, 7, 2403 (2012).

11. H. Li, J. Ren, L. Zhong, R. Sun and L. Liang, Bioresour. Technol., 176, 242 (2015); https://doi.org/10.1016/j.biortech.2014.11.044.

12. H.C. Ko, L.T. Shih, T.B. Jhan, C.F. Chang, N.Y. Wang and C.Y. Wang, BioResources, 8, 612 (2013).

13. P. O'Brien, Furfural Chemical and Biofuels from Agriculture by Wondu Business and Technology Service, Rural Industries, Research and Development Corporation (2006). 
14. A.S. Mamman, J.M. Lee, Y.C. Kim, I.T. Hwang, N.J. Park, Y.K. Hwang, J.S. Chang and J.S. Hwang, Bioprod. Biorefining, 2, 438 (2008); https://doi.org/10.1002/bbb.95.

15. R. Xing, W. Qi and G.W. Huber, Energy Environ. Sci., 4, 2193 (2011); https://doi.org/10.1039/c1ee01022k.

16. C. Sánchez, L. Serrano, M.A. Andres and J. Labidi, Ind. Crops Prod., 42, 513 (2013); https://doi.org/10.1016/j.indcrop.2012.06.042.

17. Q.Y. Liu, F. Yang, Z. Liu and G. Li, J. Ind. Eng. Chem., 26, 46 (2015); https://doi.org/10.1016/j.jiec.2014.11.041.

18. T.L.-K. Yong, N. Mohamad and N.N.M. Yusof, Procedia Eng., 148, 392 (2016); https://doi.org/10.1016/j.proeng.2016.06.495.

19. R. Suxia, X. Haiyan, Z. Jinling, L. Shunqing, H. Xiaofeng and L. Tingzhou, Carbohydr. Res., 359, 1 (2012); https://doi.org/10.1016/j.carres.2012.07.006.

20. S.K. Uppal and R. Kaur, Sugar Tech, 13, 166 (2011); https://doi.org/10.1007/s12355-011-0081-5.

21. I. Romero, E. Ruiz, E. Castro and M. Moya, Chem. Eng. Res. Des., 88, 633 (2010); https://doi.org/10.1016/j.cherd.2009.10.007.

22. M.T. García-Domínguez, J.C. García-Domínguez, M.J. Feria, D.M. GómezLozano, F. López and M.J. Díaz, Chem. Eng. J., 221, 185 (2013); https://doi.org/10.1016/j.cej.2013.01.099.

23. O. Yemis and G. Mazza, Bioresour. Technol., 102, 7371 (2011); https://doi.org/10.1016/j.biortech.2011.04.050.

24. M. Vázquez, M. Oliva, S.J. Téllez-Luis and J.A. Ramírez, Bioresour. Technol., 98, 3053 (2007); https://doi.org/10.1016/j.biortech.2006.10.017.

25. K.H. Lin, M.-H. Huang and A.C.-C. Chang, Int. J. Hydrogen Energy, 38, 15794 (2013); https://doi.org/10.1016/j.ijhydene.2013.06.088.

26. W. Wang, J. Ren, H. Li, A. Deng and R. Sun, Bioresour. Technol., 183, 188 (2015); https://doi.org/10.1016/j.biortech.2015.02.068.

27. P. Brazdausks, M. Puke, N. Vedernikovs and I. Kruma, Balt. For, 20, 106 (2014)

28. M. Martín and I.E. Grossmann, Ind. Eng. Chem. Res., 55, 3192 (2016); https://doi.org/10.1021/acs.iecr.5b03038.

29. M.P. de Paula, T.M. Lacerda, M.D. Zambon and E. Frollini, Cellulose, 19, 975 (2012); https://doi.org/10.1007/s10570-012-9674-8.

30. T.M. Lacerda, M.P. de Paula, M.D. Zambon and E. Frollini, Cellulose, 19, 351 (2012); https://doi.org/10.1007/s10570-011-9638-4

31. J.M. Hernandez-Salas, M.S. Villa-Ramirez, J.S. Veloz-Rendon, K.N. Rivera-Hernandez, R.A. Gonzalez-Cesar, M.A. Plascencia-Espinosa and S.R. Trejo-Estrada, Bioresour. Technol., 100, 1238 (2009); https://doi.org/10.1016/j.biortech.2006.09.062.
32. S. Gamez, J.A. Ramirez, G. Garrote and M. Vázquez, J. Agric. Food Chem., 52, 4172 (2004); https://doi.org/10.1021/jf035456p.

33. P. Lenihan, A. Orozco, E. O'Neill, M.N.M. Ahmad, D.W. Rooney and G.M. Walker, Chem. Eng. J., 156, 395 (2010); https://doi.org/10.1016/j.cej.2009.10.061.

34. Y. Sun, L. Lin, H. Deng, J. Li, B. He, R. Sun and P. Ouyang, BioResources, 3, 297 (2008).

35. C. Chang, G. Xu, W. Zhu, J. Bai and S. Fang, Fuel, 140, 365 (2015); https://doi.org/10.1016/j.fuel.2014.09.102.

36. Y. Xing, L. Bu, D. Sun, Z. Liu, S. Liu and J. Jiang, Bioresour. Technol., 193, 401 (2015); https://doi.org/10.1016/j.biortech.2015.06.118.

37. J. Atilio de Frias and H. Feng, Green Chem., 16, 2779 (2014); https://doi.org/10.1039/c3gc42632g.

38. K. Lin, B. Ma, Y. Sun and W. Liu, Bioresour. Technol., 167, 133 (2014); https://doi.org/10.1016/j.biortech.2014.06.022.

39. L. Zhang, G. Xi, K. Yu, H. Yu and X. Wang, Ind. Crops Prod., 98, 68 (2017); https://doi.org/10.1016/j.indcrop.2017.01.014.

40. R.E. Coronel, J.C. Zuno and R.C. Sotto, Promising Fruit of the Philippines, College of Agriculture, University of the Philippines (1986).

41. 41 V.L.A.G.D. Lima, E.D.A. Mélo and L.D. Santos Lima, Rev. Bras. Frutic., 23, 421 (2001); https://doi.org/10.1590/S0100-29452001000200045.

42. M. von Sivers and G. Zacchi, Bioresour. Technol., 51, 43 (1995); https://doi.org/10.1016/0960-8524(94)00094-H.

43. M.J. Taherzadeh and K. Karimi, BioResources, 2, 472 (2007).

44. N.R. Vinueza, E.S. Kim, V.A. Gallardo, N.S. Mosier, M.M. Abu-Omar, N.C. Carpita and H.I. Kenttämaa, Biomass Bioenergy, 74, 1 (2015); https://doi.org/10.1016/j.biombioe.2014.10.012.

45. N. Thamizhselvam, I.V. Liji, Y.R. Sanjayakumar, C.G.D. Gopi and K.G.V. Kumar, Enliven: Toxicol. Allied Clin. Pharmacol., 1, 1 (2015).

46. A. Shafeeq, A. Muhammad, S. Sarfaraz, Z. Akram, H.M.U. Saeed and U. Farooq, Int. J. Chem. Eng. Appl., 6, 381 (2015); https://doi.org/10.7763/IJCEA.2015.V6.514.

47. T.M. Lacerda, M.D. Zambon and E. Frollini, Ind. Crops Prod., 71, 163 (2015); https://doi.org/10.1016/j.indcrop.2015.03.072.

48. H.H. Kim, H.J. Ryu and K.K. Oh, Bioresour. Technol., 218, 367 (2016); https://doi.org/10.1016/j.biortech.2016.06.106.

49. R, C. Griffin, Technical Methods of Analysis, McGraw-Hill Book Co., New York, edn 2, pp. 491-494 (1921).

50. G. Andaka, J. Teknologi, 4, 180 (2011).

51. H.K. Ong and M. Sashikala, J. Trop. Agric. Food Sci., 35, 305 (2007). 